\title{
PERFORMANCE INDICATORS OF RECTANGULAR MICROSTRIP
}

\section{PATCH ANTENNA}

\author{
BISWA RANJAN BARIK ${ }^{1} \&$ A. KALIRASU ${ }^{2}$ \\ ${ }^{I}$ Research Scholar, Department of Electrical \& Electronic Engineering, AMET University, India \\ ${ }^{I}$ Faculty, Department of Electronic \& Communication Engineering, GIET(A), Rajahmundry, India \\ ${ }^{2}$ Faculty, Department of Electrical \& Electronic Engineering, SSIET, Nuzbid, India
}

\begin{abstract}
Here we have tried to give a brief idea about the effect of different parameters such as length, height, width of the patch, the permittivity of different materials and frequency on the performance of Microstrip patch antenna. The impact of different materials on efficiency and effect of fringing field on micro strip line has also been discussed based on closed form formulas. The output is based on mat-lab code which has been generated through the mathematical formulas given by the various researcher

KEYWORDS: Microstrip Patch Antenna, Performance Indicators, Radiation-Efficiency \& Fringing-Field
\end{abstract}

Received: Apr 12, 2019; Accepted: May 02, 2019; Published: Jun 11, 2019; Paper Id.: IJMPERDJUN2019159

\section{INTRODUCTION}

Microstrip Antenna was first invented by Scientist Robert E. Bob Munson (1940-2015) from the United States in the year 1972. He invented and Developed numerous MPA for nearly all U.S Programs and convinced many customers to convert to Conformal MPA instead of protruding antennas and was awarded over 30 U.S. Patents. Basically, it is a printed antenna which operates at microwave frequency greater than $1 \mathrm{GHz}$ and became famous due to its small size, light weight, conformable to planar and non-planar surfaces, easy to design, easily fabricated on PCB and MCM etc... In recent trends of wireless-Communication patch antennas are used in almost all communication device for its ease of installation and fabrication. Even though microstrip antenna has lots of advantages it is having some limitation also-like low efficiency, narrow bandwidth, low RF power, not suitable for high-power applications, etc, hence lots of research going on to improve above parameters. As its name indicates it is having only one reference plane and consists of four parts such as Ground plane, Substrate, Patch and Feeder. The basic principle of operation of the patch antenna is that when it is excited at a resonant frequency, a strong field is set up inside the cavity, and a strong current on the bottom surface of the patch which produces significant radiation. For a rectangular patch, the length $\mathrm{L}$ of the patch is usually $0.3333 \lambda_{\mathrm{o}}<\mathrm{L}<0.5 \lambda_{\mathrm{o}}$, where $\lambda_{\mathrm{o}}$ is the free space wavelength. The patch is selected to be very thin such that $\mathrm{t}<<\lambda_{\mathrm{o}}$ (where $\mathrm{t}$ is the patch thickness). The height $\mathrm{h}$ of the dielectric substrate is usually $0.003 \lambda \mathrm{o} \leq \mathrm{h} \leq 0.05 \lambda \mathrm{o}$. The dielectric constant of the substrate (cr) is typically in the range of $2.2 \leq \varepsilon r \leq 12$ [1]. Various factors directly affecting the performance of microstrip patch antenna. Ranjan Mishraet al presented an analytical study on the effects of different size and shapes of slots on the performance characteristic of UWB microstrip antenna [2]. Bikash Ranjan Behera et al projected the impact of different substrates on Rectangular Microstrip Patch Antenna' for different dimensions with differs in applications. 
The substrates taken by the author are FR-4, Rogers RO 3003 and Rogers RT Duroid 5870 at different instances [3]. Deepika $\mathrm{j}$ et al represents a brief description about the design of a rectangular microstrip patch antenna and parametric analysis in terms of return loss, bandwidth, directivity, and gain by using same and different dielectric substrate materials with same and different thickness of rectangular microstrip patch antenna. They also studied and verified the impact of parameters such as L, W, عr, and h on antenna [4]. The research carried out by the authors is not giving a clear idea about impact of the various parameter on the performance of microstrip patch antenna hence more elaborate research which gives a clean idea on performance indicator of Microstrip antenna has projected. This paper focuses on three areas such as i) Effect of various parameters on the performance of antenna ii) Relation between efficiency and permittivity of material iii)Fringing field effect of the microstripline.

\section{DESIGN EQUATION OF RECTANGULAR-MICROSTRIP PATCH -ANTENNA}

The design equation for Microstrip patch antenna can be calculated by knowing the permittivity of material and height of the patch from the substrate. The Width of the patch can be calculated as:

$$
W=\frac{C}{2 f_{0} \sqrt{\frac{\varepsilon_{r}+1}{2}}}
$$

Where $\mathrm{C}$ is the velocity of light and $\mathrm{fO}$ is the operating frequency

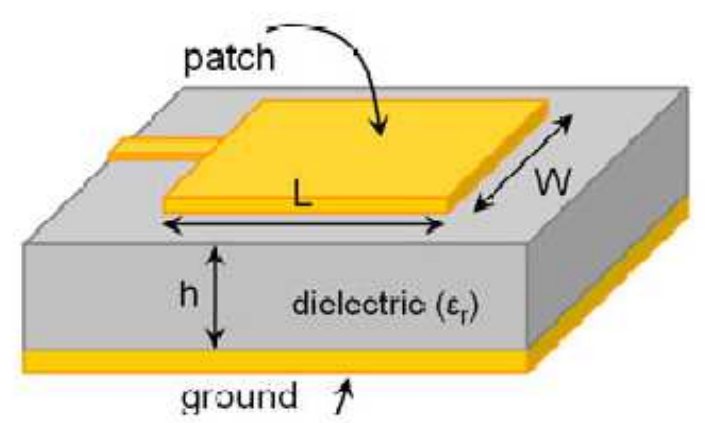

Figure 1: Rectangular MPA

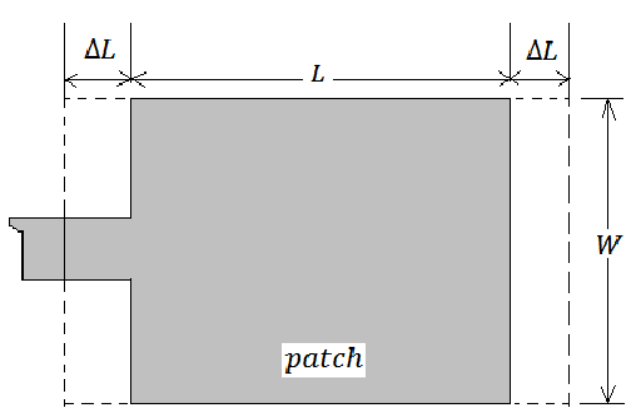

Figure 2: Effective Lengths of Patch

The reason behind the effective length in MPA is when a strong field generated by applying excitation plane waves from the patch attracted towards the ground plane and Waves at the end corner of the patch are traveling to the air and returns to the ground plane, this is also called as the fringing field effect of MPA. Due to this effect radiation occurs and more the fringing field more will be the radiation. The extra length covered by the waves known as $\Delta \mathrm{L}$. As the permittivity of air is ' 1 ' the effective permittivity is calculated based on it.

$$
\varepsilon_{e f f}=\frac{\varepsilon_{r}+1}{2}+\frac{\varepsilon_{r}-1}{2}\left[1+12 \frac{h}{W}\right]^{\frac{1}{2}}
$$

The Effective length of the Patch antenna is

$$
L_{e f f}=\frac{C}{2 f_{0} \sqrt{\varepsilon_{e f f}}}
$$


The length of Extension is calculated as

$$
\Delta L=0.412 h \frac{\left(\varepsilon_{e f f}+0.3\right)\left(\frac{W}{h}+0.264\right)}{\left(\varepsilon_{e f f}-0.264\right)\left(\frac{W}{h}+0.8\right)}
$$

The Actual length of patch given as

$$
L=L_{e f f}-2 \Delta L
$$

Total impedance of Microstrip transmission line can be calculated as

$$
Z_{L}=\sqrt{Z_{1} \times Z_{2}}
$$

Length of Microstrip line can be calculated as

$$
T L=\frac{\lambda}{4}-\frac{\lambda_{0}}{4 \sqrt{\varepsilon_{r}}}
$$

Where $\lambda_{0}=\frac{C}{f_{0}}$

Guide wavelength

$$
\lambda_{g}=\frac{\lambda_{0}}{\sqrt{\varepsilon_{\text {reff }}}}
$$

Quarter wave section length

$$
l_{\text {quarter }}=\frac{\lambda_{g}}{4}
$$

Quarter wave section width

$$
W=\frac{7.48 H}{e^{\frac{Z_{0}}{87} \sqrt{\left(\varepsilon_{r}+1.41\right)}}}-1.25 T
$$

Length and width of $50 \Omega$ termination line

$$
l_{50}=\frac{\lambda_{g}}{4}
$$




$$
\begin{aligned}
& W_{50}=\frac{10 H}{1+\varepsilon_{r}} \\
& \mathrm{LG}=\mathrm{LS}=\mathrm{WG}=\mathrm{WS} \\
& \mathrm{L}_{\mathrm{G}}=2 *(\text { Half-length of patch }+ \text { Length of quarter wave section }+ \text { length of } 50 \Omega \text { line })
\end{aligned}
$$

\section{EFFICIENCY CALCULATION OF MICROSTRIP PATCH ANTENNA}

As microstrip patch antenna is a cavity model, the expression for electric and magnetic field inside the cavity is given by [5]

$$
\hat{E}\left\{\begin{array}{l}
E_{Z}=E_{0} \cos \left(k_{g} x\right) \\
E_{x}=E_{y}=0
\end{array}\right\} \hat{H}\left\{\begin{array}{l}
H_{y}=H_{0} \sin \left(k_{g} x\right) \\
H_{x}=H_{z}=0
\end{array}\right\}
$$

Where

$$
\begin{aligned}
& K_{g}=K_{0}\left(\varepsilon_{r} \mu_{r}\right)^{\frac{1}{2}} \\
& \mathrm{~K}_{0}=\text { free space propagation constant } \\
& \varepsilon_{\mathrm{r}}=\text { Permittivity of free space } \\
& \mu_{\mathrm{r}}=\text { Permeability of free space }
\end{aligned}
$$

The magnitude of magnetic field intensity inside the cavity is given by

$$
H_{0}=j \sqrt{\frac{\varepsilon_{0} \varepsilon_{r}}{\mu_{0} \mu_{r}}} E_{0}
$$

The value of electric loss tangent is given by

$$
\tan \delta_{\varepsilon}=\frac{\varepsilon^{\prime \prime}}{\varepsilon^{\prime}}
$$

Where $\boldsymbol{\delta}_{\mathcal{E}}$ is known as skin depth of material and it is equal to $\frac{1}{\sqrt{\pi f \mu}}$. The value of $\mathcal{E}^{\prime}$ and $\mathcal{E}^{\prime \prime}$ is given by

$$
\begin{aligned}
& \mathcal{E}^{\prime}=\mathcal{E}_{o} \varepsilon_{r} \\
& \mathcal{\varepsilon}^{\prime \prime}=\varepsilon_{o} \varepsilon_{r} \tan \delta_{\varepsilon}
\end{aligned}
$$

Similarly, the value of magnetic loss tangent is given by 
$\tan \delta_{\mu}=\frac{\mu^{\prime}}{\mu^{\prime}}$

Where the value of $\mu$ ' and $\mu$ " is given by

$$
\begin{aligned}
& \mu^{\prime}=\mu_{0} \mu_{r} \\
& \mu^{\prime \prime}=\mu_{0} \mu_{r} \tan \delta_{\mu}
\end{aligned}
$$

The value of dielectric loss inside the cavity is given by

$$
P_{D}=\frac{w \varepsilon}{2} \iiint_{v}|E|^{2} d V=\frac{1}{2}\left|E_{0}\right|^{2} \frac{W d \tan \delta_{\varepsilon}}{240} \sqrt{\frac{\varepsilon_{r}}{\mu_{r}}}
$$

The value of magnetic loss inside the cavity is given by

$$
P_{M}=\frac{w \mu^{\prime \prime}}{2} \iiint_{v}|H|^{2} d V=\frac{1}{2}\left|E_{0}\right|^{2} \frac{W d \tan \delta_{\mu}}{240} \sqrt{\frac{\varepsilon_{r}}{\mu_{r}}}
$$

For the case of magnetodielectric materials having $\left(\mu_{\mathrm{r}}>1\right.$ and $\left.\varepsilon_{\mathrm{r}}>1\right)$ total loss inside the cavity is given by

$$
P_{M D}=P_{D}+P_{M}=\frac{1}{2}\left|E_{0}\right|^{2} \frac{W d\left(\tan \delta_{\varepsilon}+\tan \delta_{\mu}\right)}{240} \sqrt{\frac{\varepsilon_{r}}{\mu_{r}}}
$$

The radiation efficiency of the patch which is defined as the ratio of radiated power to that of total power can be calculated as

$$
\eta_{\text {rad }}^{\text {patch }}=\frac{P_{r a d}}{P_{r a d}+P_{M D}}=\frac{1}{1+\frac{\tan \delta_{\varepsilon}+\tan \delta_{\mu}}{240 G_{r}^{\text {patch }}} \frac{W}{d} \sqrt{\frac{\varepsilon_{r}}{\mu_{r}}}}
$$

Where

$$
P_{\text {rad }}=\frac{1}{2}\left|E_{0}\right|^{2} d^{2} G_{r}^{\text {patch }}
$$

Radiation conductance of the patch is given by 


$$
G_{r}^{\text {patch }}=\frac{4}{\pi^{2} \eta_{0}} \int_{0}^{\pi \pi} \int_{0}^{[}\left[\frac{\sin \left(\frac{k_{0} W \cos \theta}{2}\right)}{\cos \theta} \cos \left(\frac{k_{0} \pi \sin \theta \sin \phi}{2 k_{g}}\right)\right] \times(\sin \theta)^{3} d \theta d \phi
$$

The total energy stored in the patch is given by

$$
W_{T}=\frac{1}{4} \iiint_{V}\left(\varepsilon^{\prime}|E|^{2}+\mu^{\prime}|H|^{2}\right) d V=\frac{1}{2}\left|E_{0}\right|^{2} \frac{W d}{240 w} \sqrt{\frac{\varepsilon_{r}}{\mu_{r}}}
$$

The quality factor and bandwidth of the patch antenna can be calculated as

$$
\begin{aligned}
& Q=\frac{w W_{T}}{P_{r a d}+P_{M D}} \\
& B W^{\text {patch }}=\frac{1}{\sqrt{2} Q} \\
& =\frac{1}{\sqrt{2}}\left(240 \frac{d}{W} G_{r}^{\text {patch }} \sqrt{\frac{\mu_{r}}{\varepsilon_{r}}}+\tan \delta_{\varepsilon}+\tan \delta_{\mu}\right)
\end{aligned}
$$

From the above expression, we can say that when the permeability of the patch increases bandwidth of antenna increases and it decreases with an increase in permittivity of the material. Similarly the result is opposite for the case of efficiency of the patch.

\section{EFFECT OF CAPACITOR - RADIOUS ON FRINGING FIELD OF MICROSTRIP LINES}

The increasing application of integrated circuits at microwave frequencies has generated interest in the use of rectangular and circular microstrip disk capacitors as lumped element circuits. The fringing field effect of such capacitors was first observed in 1877 by Kirchhoff, who used conformal mapping to account for the fringing. But his analysis was limited by the assumption that the capacitor is air-filled, but in microstrip applications, the capacitor plates are separated by dielectric capacitor instead of microstrip lines lately others have come up with better approximate closed-form solutions to the problem taking into account the presence of dielectric material and fringing. The geometry of the circular microstrip capacitor with radius " $r$ " and separation distance $d$ is shown in figure (3). If the desk area $S\left(S=\pi r^{2}\right)$ is very large compared with the separation distance $(\sqrt{S} \gg d)$ then fringing is minimal and the capacitance is given by 


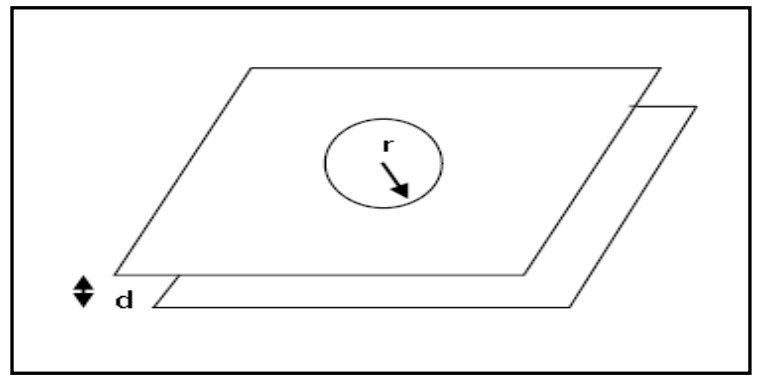

Figure 3: Circular Microstrip Capacitor

$$
C=\frac{\varepsilon_{0} \varepsilon_{r} \pi r^{2}}{d}
$$

\section{Case 1}

According to Kirchhoff [6] the fringing capacitance is

$$
\Delta C=\varepsilon_{0} \varepsilon_{r} r\left(\log \frac{16 \pi r}{d}-1\right)
$$

The total capacitance of microstripline

$$
C_{T}=\frac{\varepsilon_{0} \varepsilon_{r} \pi r^{2}}{d}+\varepsilon_{0} \varepsilon_{r} r\left(\log \frac{16 \pi r}{d}-1\right)
$$

\section{Case 2}

According to Chew and Kong [7], the total capacitance including fringing is

$$
C_{T}=\frac{\varepsilon_{0} \varepsilon_{r} \pi r^{2}}{d}\left\{1+\frac{2 d}{\pi \varepsilon_{r} r}\left[\ln \left(\frac{r}{2 d}\right)+\left(1.41 \varepsilon_{r}+1.77\right)+\frac{d}{r}\left(0.268 \varepsilon_{r}+1.65\right)\right]\right\}
$$

\section{Case 3}

Wheeler used interpolation to match the three cases of small, medium, and large disk sizes. According to Wheeler [8]

$$
C_{K S}=\varepsilon_{0} r\left[4\left(1+\varepsilon_{r}\right)+\frac{\varepsilon_{r} \pi r}{d}\right]
$$

Where $\mathrm{K}=\varepsilon_{\mathrm{r}}$, when $\mathrm{K}=1$ equation (35) becomes

$$
C_{1 S}=\varepsilon_{0} r\left[8+\frac{\pi r}{d}\right]
$$

Total capacitance is given by 
$C_{T}=\frac{C_{K S}}{K_{c} C_{1 S}} C_{1}+\left(1-\frac{1}{K_{c}}\right) C_{2} C_{K S}$

where

$$
\begin{aligned}
& C_{1}=\varepsilon_{0} r\left[8+\frac{\pi r}{d}+\frac{2}{3} \ln \left(\frac{1+0.8\left(\frac{r}{d}\right)^{2}+\left(\frac{0.31 r}{d}\right)^{4}}{1+0.9\left(\frac{r}{d}\right)}\right]\right] \\
& C_{2}=1-\frac{1}{4+2.6 \frac{r}{d}+2.9 \frac{d}{r}} \\
& K_{C}=0.37+0.63 \varepsilon_{r}
\end{aligned}
$$

\section{RESULTS AND DISCUSSIONS}

A mat-lab code has been generated to know the impact of the various parameter on the performance of microstrip patch antenna. Table 1 shows the impact of permittivity on the width and length of MPA. Here the operating frequency and height keep constant as $2.4 \mathrm{GHz}$ and $5 \mathrm{~mm}$ respectively.

Table 1: Impact of Dielectric Constant on Width \& Length of MPA

\begin{tabular}{|c|c|c|c|c|c|}
\hline Frequency & $\begin{array}{c}\text { Dielectric Height } \\
(\mathbf{H})(\mathbf{m m})\end{array}$ & $\left(\boldsymbol{\varepsilon}_{\mathbf{r}}\right)$ & Impedance & $\begin{array}{c}\text { Width of Patch } \\
(\mathbf{W})(\mathbf{m m})\end{array}$ & $\begin{array}{c}\text { Length of Patch } \\
(\mathbf{L})(\mathbf{m m})\end{array}$ \\
\hline $2.4 \mathrm{GHz}$ & 5 & 1 & 90 & 62.5 & 55.57 \\
\hline $2.4 \mathrm{GHz}$ & 5 & 2 & 135 & 51.03 & 40.79 \\
\hline $2.4 \mathrm{GHz}$ & 5 & 3 & 180 & 44.19 & 33.59 \\
\hline $2.4 \mathrm{GHz}$ & 5 & 4 & 225 & 39.52 & 29.13 \\
\hline $2.4 \mathrm{GHz}$ & 5 & 5 & 270 & 36.08 & 26.02 \\
\hline $2.4 \mathrm{GHz}$ & 5 & 6 & 315 & 33.40 & 23.69 \\
\hline $2.4 \mathrm{GHz}$ & 5 & 7 & 360 & 31.25 & 21.86 \\
\hline $2.4 \mathrm{GHz}$ & 5 & 8 & 405 & 29.46 & 20.37 \\
\hline $2.4 \mathrm{GHz}$ & 5 & 9 & 450 & 27.95 & 19.13 \\
\hline
\end{tabular}

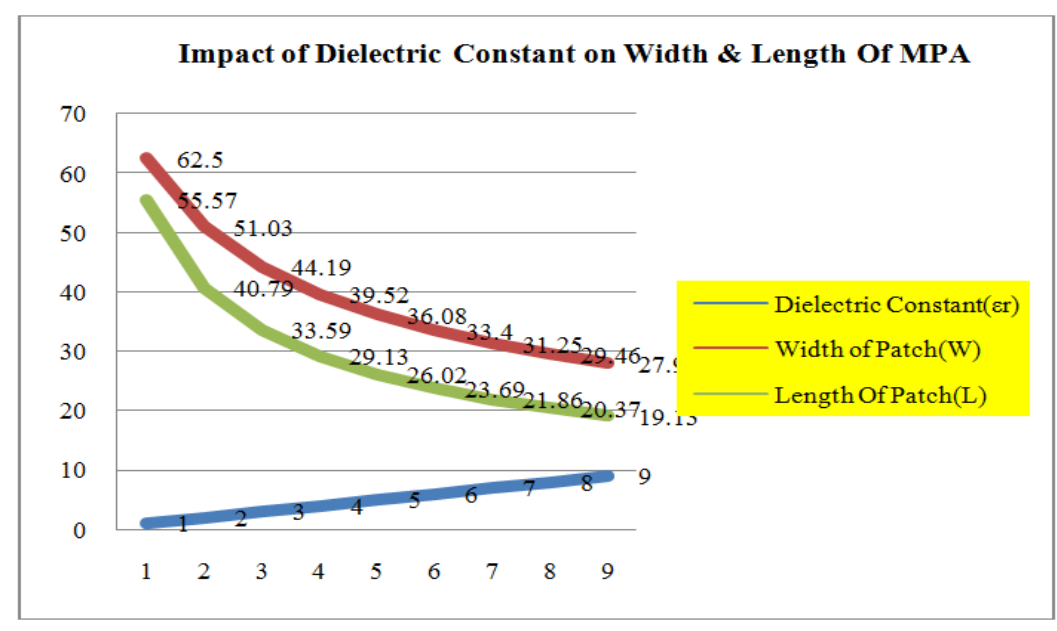

Figure 4: Impact of Dielectric Constant on Width \& Length of MPA 
From the above result output, it has shown clearly that by increasing permittivity the value of matching impedance increases whereas width and length of patch decreases exponentially.

Table 2: Impact of Height on Width \& Length of MPA at $2.4 \mathrm{GHz}$

\begin{tabular}{|c|c|c|c|c|c|}
\hline Frequency & $\begin{array}{c}\text { Dielectric Height } \\
(\mathbf{H})(\mathbf{m m})\end{array}$ & $\left(\boldsymbol{\varepsilon}_{\mathbf{r}}\right)$ & $\mathbf{Z}$ & $\begin{array}{c}\text { Width of Patch } \\
(\mathbf{W})(\mathbf{m m})\end{array}$ & $\begin{array}{c}\text { Length of Patch } \\
(\mathbf{L})(\mathbf{m m})\end{array}$ \\
\hline $2.4 \mathrm{GHz}$ & 3 & 1 & 90 & 62.5 & 58.27 \\
\hline $2.4 \mathrm{GHz}$ & 6 & 1 & 90 & 62.5 & 54.26 \\
\hline $2.4 \mathrm{GHz}$ & 9 & 1 & 90 & 62.5 & 50.42 \\
\hline $2.4 \mathrm{GHz}$ & 12 & 1 & 90 & 62.5 & 46.75 \\
\hline $2.4 \mathrm{GHz}$ & 15 & 1 & 90 & 62.5 & 43.23 \\
\hline $2.4 \mathrm{GHz}$ & 18 & 1 & 90 & 62.5 & 39.84 \\
\hline $2.4 \mathrm{GHz}$ & 21 & 1 & 90 & 62.5 & 36.57 \\
\hline $2.4 \mathrm{GHz}$ & 24 & 1 & 90 & 62.5 & 33.41 \\
\hline $2.4 \mathrm{GHz}$ & 27 & 1 & 90 & 62.5 & 30.36 \\
\hline $2.4 \mathrm{GHz}$ & 30 & 1 & 90 & 62.5 & 27.39 \\
\hline
\end{tabular}

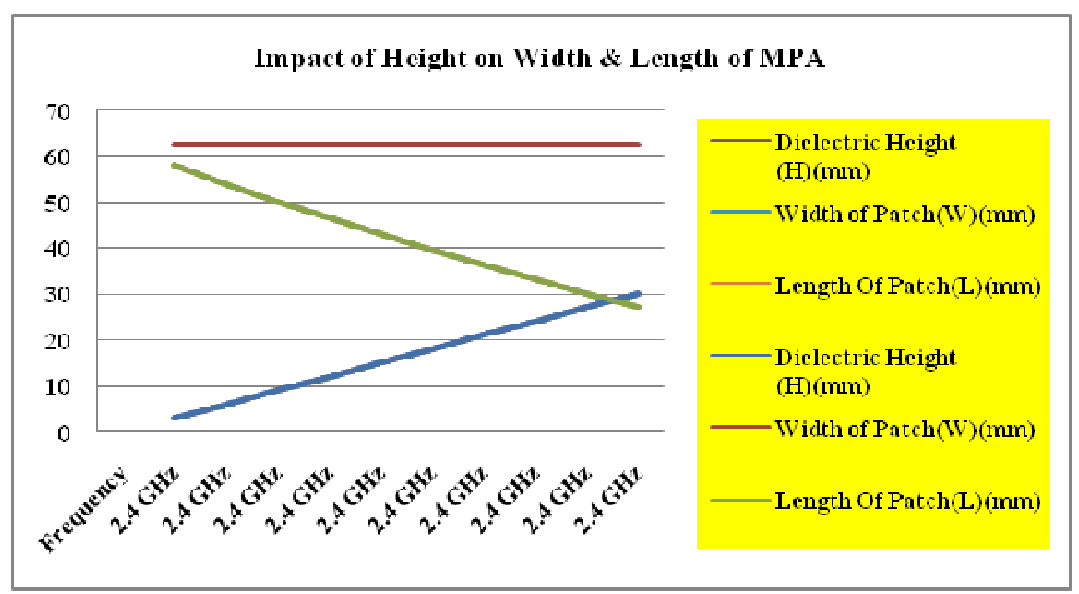

Figure 5: Impact of Height on Width and Length of MPA

To know the impact of height on width and length of MPA we keep the frequency and permittivity of the material constant i:e $2.4 \mathrm{GHz}$ and ' 1 ' respectively. By varying the value of height from low to high its effect on length and width of the patch has calculated. From the above result output, we got that with an increase in height i:e distance from the substrate to patch the length of patch decreases linearly whereas it is having no effect on the width of patch. The condition in this part is that we can increase the height up to a threshold level because beyond that there will be no radiation occurs on patch.

Table 4: Impact of Frequency on Width \& Length of MPA

\begin{tabular}{|c|c|c|c|c|c|}
\hline $\mathbf{F}(\mathbf{G H z})$ & $(\mathbf{H})(\mathbf{m m})$ & $\left(\boldsymbol{\varepsilon}_{\mathbf{r}}\right)$ & $\mathbf{Z}(\mathbf{o h m})$ & $\begin{array}{c}\text { Width of } \\
\text { Patch(W) } \\
(\mathbf{m m})\end{array}$ & $\begin{array}{c}\text { Length of } \\
\text { Patch(L) } \\
(\mathbf{m m})\end{array}$ \\
\hline 1 & 5 & 1 & 90 & 150 & 143 \\
\hline 2 & 5 & 1 & 90 & 75 & 68.03 \\
\hline 5 & 5 & 1 & 90 & 30 & 23.36 \\
\hline 7 & 5 & 1 & 90 & 21.42 & 14.98 \\
\hline 9 & 5 & 1 & 90 & 16.66 & 10.40 \\
\hline 25 & 5 & 1 & 90 & 6 & 0.75 \\
\hline 26 & 5 & 1 & 90 & 5.76 & 0.56 \\
\hline 28 & 5 & 1 & 90 & 5.17 & 0.09 \\
\hline
\end{tabular}




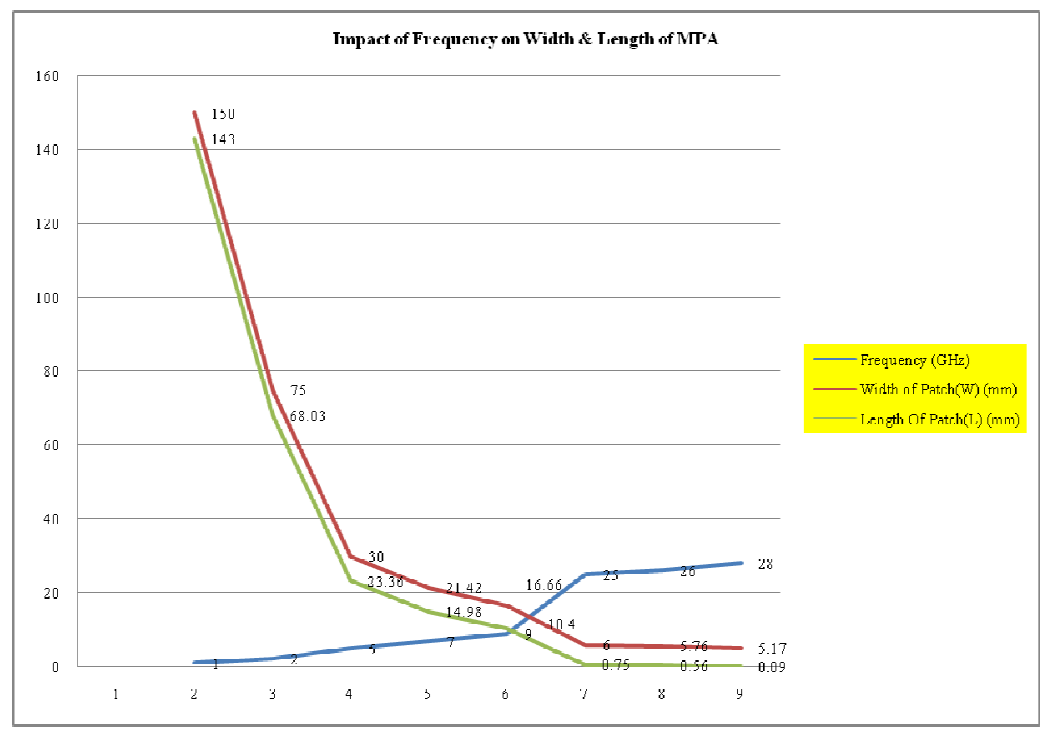

Figure 6: Impact of Frequency on Width \& Length of MPA

To know the impact of frequency on width and length of MPA we keep the height, permittivity and characteristics impedance constant I:e 5mm,1 and 90 ohm respectively. By varying value of frequency from $1 \mathrm{GHz}$ to $28 \mathrm{GHz}$ its effect on width and length of the patch has calculated. From the above result output, we got that by increasing the operating frequency the value of width and length decreases drastically. From the result outputting it has also shown that by increasing the value of frequency from $1 \mathrm{Ghz}$ to $2 \mathrm{Ghz}$ the value of width and length decreases near to half of its initial value.

We can also say that it is practically difficult to design a rectangular microstrip patch antenna for frequency more than $28 \mathrm{GHz}$ with the material having permittivity value equal to ' 1 '. whereas higher frequency microstrip antenna can be designed by taking higher permittivity material or by using array techniques.

To know the effect of dielectric constant on radiation efficiency, we have taken the general equation (25) of MPA and developed a Mat-lab code for it.

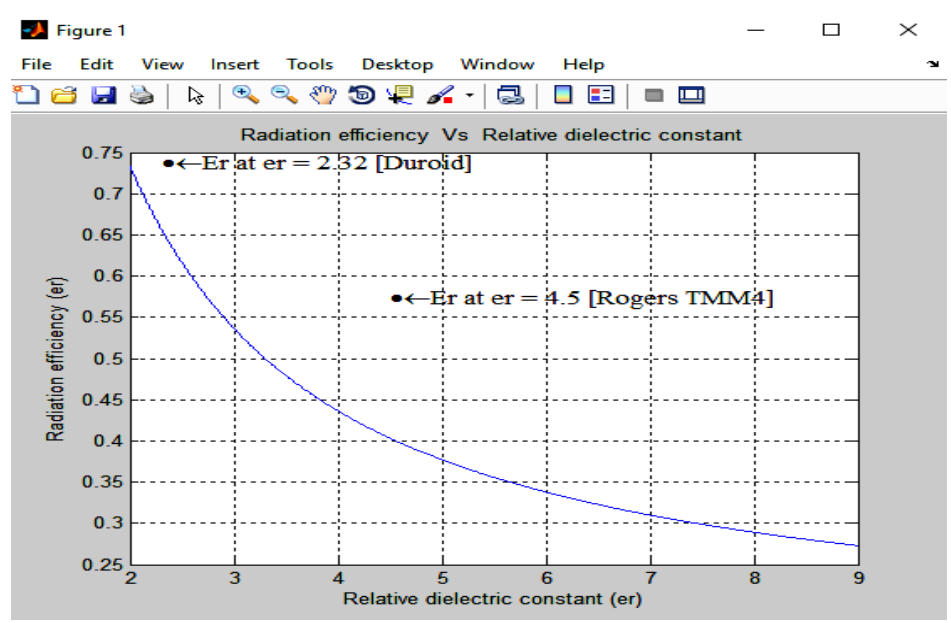

Figure 7: Relation between Radiation Efficiency and Dielectric Constant 
From the above-simulated output, we can say that the patch made with a higher value of relative dielectric constant posses less radiation efficiency whereas its value is high for material with a lower dielectric constant.

In the modern era of high-frequency application, proper care is required while sending a signal from the transmitter to the receiver. In such high speed communication one bad bit dramatically affect the whole signal and unwanted delay and glitches occurs at output if it is not handled properly. As signal transmitted through transmission line which is made up of capacitor, it plays a vital role to maintain the quality of the signal. The unwanted fringing field generated from the capacitor increases chances of crosstalk and electromagnetic interference in the signal which also increases the delay of the signal. Hence to know the effect of capacitor on fringing field we have developed a mat-lab code from the equation $(33),(34),(35)$

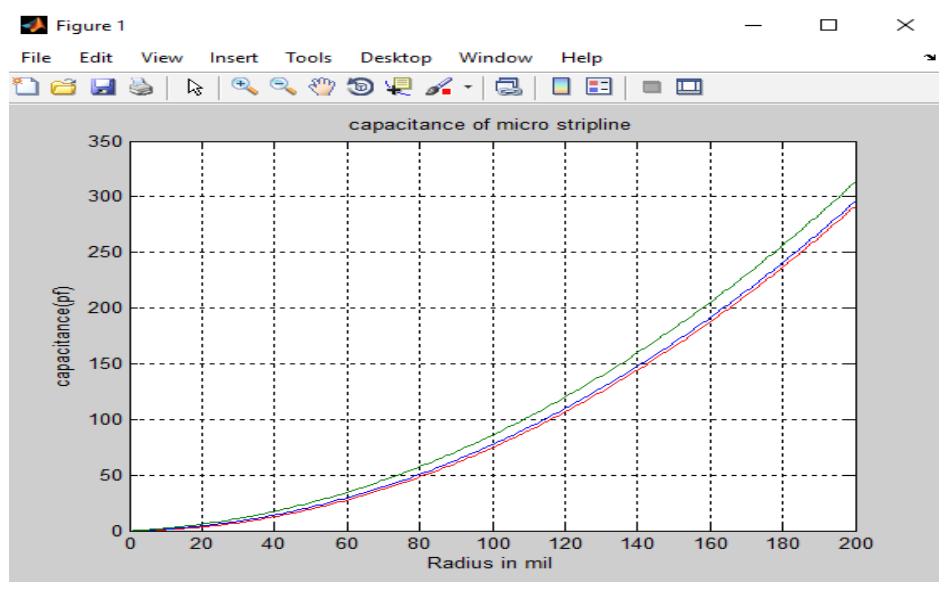

Figure 8: Relation Between Capacitor Radius and Fringing Capacitance of Microstripline

From the above result output, we got that by increasing the radius of capacitor the fringing field capacitance of microstrip line increases which can increase electromagnetic interference with other circuit and direct effect on signal integrity. Hence it is advisable to use relatively small radius capacitor microstrip lines while designing antenna in PCB to improve signal quality and to reduce EMI.

\section{CONCLUSIONS}

Here we have discussed the effect of different parameters such as length, height, the width of the patch, the permittivity of different materials and frequency on the performance of microstrip patch antenna. The impact of different materials on efficiency and effect of the fringing field on microstrip line has also discussed. The resulting output is the performance indicator of a rectangular microstrip patch antenna which will help the future researcher to get a clean idea on it.

\section{REFERENCES}

1. Biswa Ranjan Barik \& A. Kalirasu, Designing Of Trapezium Cut Shape Microstrip Antenna In X Band, International Journal of Electrical and Electronics Engineering Research (IJEEER) ISSN(P): 2250-155X; ISSN(E): 2278-943X,Special Issue, Nov 2016, $145-152$

2. Ranjan Mishra, Raj Gaurav Mishra, Piyush Kuchhal. Analytical Study on the Effect of Dimension and Position of Slot for the Designing of Ultra Wide Band (UWB) Microstrip Antenna, 2016 Intl. Conference on Advances in Computing, Communications and Informatics (ICACCI), Sept. 21-24, 2016, Jaipur, India DOI: 10.1109/ICACCI.2016.7732093 
3. Bikash Ranjan Behera, Priyadarshi Suraj, Effect of Substrates on Metamaterial Based Antenna Design and Analysis of Antenna using Different Substrates. 2016 international conference on wireless communication, signal processing and networking(WiSPNET), 23-25 March 2016, DOI: 10.1109/WiSPNET.2016.7566216

4. Deepika J,M. Mathivanam, A. Muruganandham,Vivek.R, Parametrical Variation And Its Effects On Characteristics Of Microstrip Rectangular Patch Antenna,2017 Second International Conference On Electrical, Computer And Communication Technologies(ICECCT), DOI: 10.1109/ICECCT.2017.8117913

5. Constant Niamien, Sylvain Collardey, Ala Sharaiha, Senior Member, Ieee, And K. Mahdjoubi, Member, IEEE, Compact Expressions For Efficiency And Bandwidth Of Patch Antennas Over Lossy Magneto-Dielectric Materials, IEEE Antennas And Wireless Propagation Letters, Vol. 10, 2011

6. L. D. Landau and E.M.Lifshitz, Electrodynamics of Continous media,Oxford Pergamon Press 1960 p.20

7. W.C.Chew and J.A.Kong, "Effects of fringing field on the capacitance of circular microstrip disk,"IEEE Transaction on Microwave Theory and Techniques, Vol 28,no 2,Feb 1980, pp 98-103

8. H.A.Wheeler, "A simple formula for the capacitance of a disc on dielectric on a plane" IEEE Transaction on Microwave Theory and Techniques, Vol 30,no 11,Nov 1982 pp 2050-2054

9. Kumar, A., Prasad, M., \& Mishra, K. P. (2013). Comparative study of effect of different parameters on performance and emission of biomass cook stoves. International Journal of Research in Engineering \& Technology, 1(3), 121-126.

10. C.A. Balanis, “Antenna Theory, Analysis amd Deign”, John Wiley \& Sons, INC, New york1997

11. John D Kraus, Manhefka, Khan, “Antenna and Wave Propogation”, Fourth edition.

12. R. Garg, P. Bhartia, I. Bahl and A. Ittipiboon, Microstrip Antenna Design Handbook, Artech House, 2000

13. Wareen L. Stutzmen, Gary A Thicle, “Antenna Theory and Design”, second edition, Johnwiley \& Sons,INC, 1998 